\title{
Ideologias totalitárias nas práticas educativas
}

José João Neves Barbosa Vicente*

\section{Resumo}

A forma de governo que no século XX assustou o mundo "civilizado" por ter negado de forma total a pluralidade dos homens (colocando o "Estado" como a única voz do mundo e o único capaz de dizer a verdade), classificada por Arendt como "totalitarismo", teve o seu fim, para alguns, com a queda de seus líderes. Essa visão é superficial e simplista, pois leva em consideração apenas a forma de governo como instituição. Na verdade, a parte mais forte e importante dela, a sua ideologia, nunca morreu, nunca foi destruída. Essa ideologia, ou seja, a ideia de "criar" ou de "fabricar" homens conforme a vontade do "dirigente" está presente e de maneira ativa ainda entre nós e, com mais incidência, no campo da educaçáo, especificamente no campo de interesse deste artigo - na educação escolar. Desse modo, entende-se a necessidade de se discutir essa questão no nosso tempo, apontando o rastro da ideologia totalitária impregnado nas práticas escolares, por meio de objetivos e métodos de procedimentos utilizados que, no fundo, refletem as intençôes e interesses dos educadores, deixando-se de lado, assim, os educandos. Açốes essas que, na sua essência, ao esquecerem a especificidade do educando e a sua capacidade criativa, destroem o sentido da educaçáo, criando indivíduos semelhantes aos súditos dos regimes totalitários: funcionam, mas não pensam.

Palavras-chave: totalitarismo, educaçâo, educadores, educandos.

\section{Totalitarian ideologies in educational practice}

\section{Abstract}

For some people, the form of government which in the twentieth century terrified the 'civilized' world by totally denying the plurality of people, making the 'State' the world's only voice and claiming that it alone was capable of telling the truth was classified by Arendt as 'totalitarianism', which came to an end with the fall of its leaders. This view is superficial and simplistic, as it only takes the form of government as an institution into consideration. In fact, the most powerful and significant component of this form of government, its ideology,

* Professor de Filosofia do Centro de Formação de Professores (CFP) da Universidade Federal do Recôncavo da Bahia (UFRB). E-mail: josebvicente@bol.com.br. 
has never died, has never been destroyed. That ideology, namely, the idea of 'creating' or 'making' people according to the will of 'leader' is present and still active and has greatest influence in the field of education and schooling which is the specific focus of this article. Hence, the need to discuss the issue of education in our time, pointing out the traces of totalitarian ideology impregnated in educational practices in schools, through their goals and methodology, which in essence, reflect the intentions and interests of educators while forgetting the learners. These actions which essentially neglect the specific requirements of learners and their creative ability, destroy the meaning of education, and form people similar to the subjects of totalitarian regimes, people who work but do not think.

Keywords: totalitarianism, education, educators, learners.

No século XX, um fenômeno político batizado de "totalitarismo", um termo que apareceu pela primeira vez em 1925 , inventado, ao que parece, por Mussolini e popularizado desde os anos 1930, amplamente estudado por Arendt (1989, p. 469) - que o delimitou no tempo e no espaço: a ditadura do nacional-socialismo, a partir de 1938, e a ditadura bolchevista, a partir de 1930 -, assombrou o continente europeu, espaço onde tinha surgido a democracia. Na expressáo de Touraine (1996, p. 10), o fenômeno totalitário ou o ódio à democracia foi "a maior desgraça" experimentada no continente. Destruiu todo o tipo de açáo autônoma dos atores sociais, devorou a sociedade civil, arrancou o indivíduo de seu meio local ou religioso para ser mobilizado ao serviço do Estado, seja este leigo ou religioso. Acabou, também, com todas as pertenças culturais do indivíduo, transformou a sociedade numa multidão de massa dócil à palavra e às ordens de um chefe. Destruiu tudo e qualquer espaço público onde se debatem as escolhas.

Todas essas açôes totalitárias tinham uma proposta "educativa", com objetivos claros: produzir cidadãos ideais que seguissem incondicionalmente as ordens do "Chefe", ou, em outros termos, educar os cidadáos para funcionar e não para pensar. Para isso, o totalitarismo libertou-se de tudo o que era capaz de oferecer-lhe resistência. Libertou-se da legalidade e se colocou acima de qualquer objetividade e estabilidade da lei positiva: o "Chefe" decidia o que era bom e prejudicial para o povo, inclusive, quem deveria morrer; libertou-se da realidade por meio da ideologia: expressão da vontade do "Chefe" que desprezava totalmente os fatos e as opinióes. A ideologia era o instrumento básico da explicação, mobilizado para que ninguém jamais começasse a pensar ou, pelo menos, para tornar o pensamento dos indivíduos "impotente, irrelevante e sem influência para o sucesso ou fracasso do poder" 
(Bauman, 2000, p. 94). Por último, o totalitarismo libertou-se da pluralidade, ao exigir a unanimidade e não tolerar nenhum tipo de debate de opinióes.

Não há como negar, hoje, a presença do totalitarismo "como uma ideologia [...] ainda entre nós" (Macridis, 1982, p. 199), como uma possibilidade inscrita na lógica do pensamento ocidental, um fenômeno potencialmente presente em tendências universais que, dadas certas condiçôes sociais, emerge dos subterrâneos da mente e converte-se em comportamento. No campo educacional, essa ideologia encontra-se em plena atividade. Ou seja, na sua essência, a proposta educativa caminha a passos largos, para o mesmo rumo do sonho totalitário: produzir seres educados que agem, incondicionalmente, de acordo com a intenção e vontade dos seus educadores. Dessa forma, ela não permite que o indivíduo desenvolva seu próprio pensamento, suas criatividades e suas propostas, mas que ele caminhe na direçâo apontada pelo seu educador. $O$ processo todo funciona por meio de regras, normas e objetivos preestabelecidos a serem seguidos e atingidos, sem possibilidades mínimas de serem mudados. $\mathrm{Na}$ verdade, antes mesmo de se iniciar uma atividade, o educador já tem prontos os resultados.

Está claro, portanto, que as análises levadas a cabo neste artigo se centralizarão, fundamentalmente, no campo da escola e na relação educador/ educando ou professor/aluno. Nesse campo e nessa relação, as tendências totalitárias se manifestam pelos métodos e objetivos pedagógicos traçados pelos educadores, que começam com a elaboração e apresentação do plano de curso, que, geralmente, trata de assuntos e objetivos de interesse do educador e, raramente, dos educandos. Assim, o plano reflete, no fundo, uma autoridade aparente do educador, que, ao longo da sua execução, funcionará, basicamente, como imposição de ideias que transformam os educandos em uma massa sem iniciativa própria, absolutamente apta à obediência, contrariando, desse modo, todo o sentido e finalidade da educaçáo, que tem como regra de ouro possibilitar ao indivíduo que pense. Essa prática de impor aos outros o que eles devem apreender, característica essencial do processo educacional atual, típico do pensamento totalitário, conduz o indivíduo ao funcionamento, mas não ao pensar.

Um exemplo emblemático desse tipo de educação pode ser encontrado na pessoa de Adolf Eichmann, alguém que aprendeu de forma exemplar a funcionar, mas não aprendeu, ou pelo menos não lhe foi permitido aprender, a pensar, conforme relato de Arendt (1999). Eichmann tinha co- 
nhecimento, convicções, argumentos, em resumo, possuía um discurso que supunha a presença de uma vida interior; porém, apesar de não dar mostras de estupidez, suas afirmaçóes revelam "total ausência de pensamento". O criminoso de guerra não parecia monstruoso nem demoníaco, e, sim, uma pessoa qualquer; sua vida pessoal talvez náo fosse "a de um criminoso", mas era certamente a de um homem incapaz de pensar. Ele era, contudo, um sujeito, e mesmo durante seu processo, um sujeito de direito; mas lhe era impossível tomar consciência de seus atos e percebê-los como maus, porque lhe era impossível captá-los sob uma luz diferente da sua, ou seja, foi educado para receber ordens, para funcionar e não para pensar. Se tivesse feito isso uma vez, uma única vez, ele teria suspendido, parado, talvez, essa máquina administrativa de que se orgulhava tanto, composta por engrenagens contínuas de ordens, regras e procedimentos, que fazia dele o elo inconsciente de uma gestão que não tinha outro fim senão a morte.

No caso da instituição escolar, substitui-se a constituição do homem em sua humanidade ou, como dizia Kant (1970), em seu fim último pela função docente. Por sua vez, como afirmei em outro texto (Vicente, 2006), a função docente é reduzida aos procedimentos didáticos que são postos em prática, os quais, finalmente, vão degenerar-se em procedimentos mecânicos, cujos florôes pedagógicos mais conhecidos são os questionários de múltiplas escolhas e os exercícios para completar. No entanto, para se entender melhor a "tendência totalitária" no campo educacional atual, como mencionado anteriormente, é mister buscar suas razóes, ou melhor, suas raízes.

As teses "progressistas" de Dewey (1931), expressas, primeiramente, em uma série de artigos de 1886 a 1902, condensam sua experiência na escola da Universidade de Chicago, da qual havia feito um laboratório. Ele não reconhecia mais na escola um lugar de estudos, especificamente, mas, sim, um centro social onde devia organizar as atividades do grupo de alunos segundo modelo da "sociedade democrática". Ainda que ele, no prefácio do seu tratado School of tomorrow (Dewey, 1931), invoque Platáo e Rousseau, que nunca viram na escola um modelo de experimentação democrática, suas teorias consistem em identificar a educação escolar e a adaptação social para melhor satisfazer as aspiraçóes igualitárias. Dewey tem, de fato, uma verdadeira fé na realidade democrática que deve ser construída muito cedo, a partir do interior, nessa sociedade reduzida que é a escola, recusando toda a realidade exterior. Transfere, dessa forma, à instituição escolar, doravante 
integrada ao universo social, a responsabilidade de constituir uma experiência democrática. Para Dewey (1940, p. 226-227), todas as outras formas de "fé moral e social" se assentam na ideia de que a experiência "deve ser submetida, a qualquer momento a alguma forma de controle exterior, alguma 'autoridade' que se supõe existir fora do processo da experiência”. A democracia está, ao mesmo tempo, no fato de que o processo da experiência é mais importante que qualquer outro resultado particular obtido, "tanto que os resultados particulares alcançados só têm um valor último na medida em que são utilizados para enriquecer e ordenar o processo em curso".

A ideia central da pedagogia de Dewey equivale a assimilar a ação educativa, orientada para fins e sancionada por resultados, ao processo vital da consciência individual, ligada à "consciência social da raça" (Dewey, 1957, p. 92). O processo comanda aqui rigorosamente o fim, a tal ponto que os resultados particulares só têm "valor último" se virem alimentar o ciclo infinito dos "processos em curso". Isso quer dizer, muito simplesmente, submeter a educação à vida nas suas diversas manifestaçóes biológicas e sociais. Dewey (1957, p. 95-96) acredita, portanto, que a escola seja, em primeiro lugar, "uma instituição social". Sendo a educação "um processo social", ela é simplesmente "essa vida comunitária" na qual estão concentrados todos os meios de ação mais eficazes para levar a criança a "tirar partido dos bens herdados da raça" e a empregar suas próprias capacidades "para fins sociais". Ele acredita "que a educação seja, portanto, um processo de vida e não uma preparação para a vida”.

Entende-se, doravante, que a educação deve introduzir-se no mundo da vida, no duplo sentido biológico e social do termo, sendo a vida assimilada ao ciclo dos processos que garantem a permanência do desenvolvimento ontogenético e filogenético da espécie humana. Esse sofisma naturalista leva a famosa fórmula de Dewey, learning by doing ("aprender fazendo"), a ser interpretada como learning by living ("aprender vivendo"), mas não como learning by thinking ("aprender pensando"). Resulta desse postulado de equivalência entre educação e vida, vida e processos, que a educação será concebida como um processo vital infinito, formado por procedimentos de ensino que só remetem a si mesmos e não a uma fonte externa. Assim como a ética e a política modernas, a educação dá, aqui, sua guinada procedimental e inverte a relação natural das coisas. Durkheim (1975) já havia proposto em Les régles de la méthode sociologique substituir o conceito de "finalidade" 
pelo conceito de "função", para descrever o papel efetivo que uma instituição desempenha na sociedade.

A inversão pedagógica, acompanhada por um recurso incessante às ciências da educação que devem coroar essas práticas, já não situa o saber nos conteúdos substanciais a ensinar ao aluno, mas nos métodos formais que se fecham em seus próprios procedimentos. É o que ocorre, por exemplo, com a chamada pedagogia por objetivos, cujo projeto já se encontra desconsiderado pela sigla, que depende, como toda a sigla, de um processo de etiquetagem e não de uma reflexão criadora de sentido. Isso equivale a um parcelamento dos conteúdos de pensamento e a uma fragmentação da inteligência dos alunos. Centrar a pedagogia em objetivos é centrar a educação no sujeito que os visa, ocultando os conteúdos reais do saber, os quais, de sua parte, são indiferentes às intenções subjetivas e aos processos objetivos, em razão de sua autonomia. A preocupação procedimental das ciências da educação, ligada ao processo dissociador do entendimento, substituem o fim ideal da pedagogia por um conjunto de objetivos virtuais que impóem aos diversos atores, professores e alunos o comportamento adequado. Isso significa dissolver o homem.

Esse tipo de pedagogia, que instrumentaliza o sujeito em uma série de procedimentos regulados pelo pedagogo e, por meio dele, pelos procedimentos analíticos das ciências nas quais ele se apoia, provém diretamente do behaviorismo de Watson no começo do século XX. Sabe-se que essa psicologia do comportamento, contemporânea do taylorismo na indústria, desenvolveu-se a partir de experimentos em psicologia animal: o comportamento é definido como a resposta observável do sujeito a uma dada série de estímulos, os quais, por sua vez, são construídos pelo experimentador segundo uma série de processos analíticos.

Não estamos mais no mundo do pensamento nem no mundo do conhecimento, e, sim, no laboratório experimental das condutas, as quais se exprimem unicamente em termos de funcionamento e pertencem, por isso, à função pedagógica. O comportamento do aluno, a partir de então, é determinado, em última instância, por um funcionamento correto ou incorreto, cujo sentido é inútil procurar, visto que, na linha de Durkheim (1975), a função deve substituir a finalidade, quer dizer, a significação dos nossos atos. Para dizê-lo mais claramente, o "sentido" de um ato pedagógico, por exemplo, o sentido que o aluno descobre lendo um poema, indo 
além do poema ao refletir sobre seus próprios sentimentos, escapa à forma de procedimento didático.

Reduzir, portanto, a educação, ainda que reforçada pelo espartilho das ciências humanas, sociais e naturais, a uma pedagogia dos objetivos, significa reduzir o ensino a um mosaico de procedimentos parcelares que, em contrapartida, parcelam seus utilizadores. Um objetivo é, com efeito, uma capacidade física ou intelectual que não pode ser diretamente observada, uma vez que ele é projetado no futuro, mas que induz no presente comportamentos observáveis e mensuráveis. Para observar corretamente esses comportamentos e dar-lhes uma medida adequada, é preciso decompô-los e hierarquizá-los, submetendo o ator, neste caso o aluno, a uma série determinada de procedimentos analíticos. O círculo pedagógico que define os procedimentos por meio de objetivos a atingir, assim como os objetivos por meio de procedimentos a utilizar, chega necessariamente à constituição de um sujeito procedimental privado de qualquer horizonte de significação.

As práticas da pedagogia por objetivos, portanto, não passam de espelhos embaçados ou de chamas mortas incapazes de iluminar a alma do aluno. São incapazes de apreciarem o pensamento e de enriquecerem os conhecimentos do aluno. $\mathrm{O}$ recurso aos novos métodos pedagógicos, invocado insistentemente para se opor ao peso dos conteúdos do ensino, tende, necessariamente, a encerrar o indivíduo em uma instrumentalizacão psicológica, pedagógica e estatística que apenas conhece as regras internas de seu funcionamento. A apreciação dos objetivos pedagógicos e dos resultados subjetivos dos alunos reduz-se cada vez mais a um simples controle da conformidade com os procedimentos implementados e com os objetivos definidos de maneira completamente exterior às condições do ensino. Ou seja, reduz-se ao conformismo intelectual e social.

Essa prática, logo, é limitada - isso para não dizer perigosa. Nesse processo todo, o professor é um emissor que codifica uma mensagem; o aluno, um receptor que decodifica a mensagem; os conhecimentos não são um saber dotado de significação substancial e, sim, uma informação ligada a um fluxo máximo transmitido pelo canal de comunicação; e o ensino náo é um esforço de pensamento crítico, mas uma soma indeterminada de informaçóes das quais é preciso apoderar-se. Isso explica, de certa forma, o motivo pelo qual o aluno fica mudo, não pensa e não é criativo. Afinal, ele foi reduzido a um sujeito - receptor de informaçóes definido em termos formais, sem a menor 
alusão aos conhecimentos reais que ele poderia adquirir, ao espírito crítico que deveria desenvolver ou despertar e ao exercício pessoal de um pensamento que se encontra preso, sob uma avalancha de siglas. Não há escapatória, o próprio de uma função, mesmo qualificada de pedagógica, é funcionar, e o funcionamento nunca pode substituir o pensamento no homem.

Pensar não é "funcionar", ou seja, conduzir sua ação segundo uma série de procedimentos previamente definidos. O tipo de pedagogia mencionado encaixa-se perfeitamente numa educação totalitária, ou melhor dizendo, numa "não educação". De deriva em deriva e de processos em procedimentos, a pedagogia moderna deixou de julgar o aluno pelo pensamento e deixou de apreciar seus conhecimentos em virtude do domínio sobre eles. Ela estabelece, em um rosário contínuo, "avaliaçôes somativas", "notas", ou "avaliaçōes formativas", "apreciaçôes", que escondem o processo de aprendizagem sem se interessar pelo conteúdo real do ensino e, evidentemente, por aquilo que o aluno sente, pensativo, perante esses métodos que o submetem ao conformismo pedagógico. Não se deve aceitar, em nenhuma circunstância, a redução do pensamento do aluno a um funcionamento. Os procedimentos não podem tomar primazia sobre os conhecimentos reais dos alunos e sobre a finalidade ideal da educação.

Essa educação funcional, comandada por um jogo de procedimentos sociais, econômicos e políticos que se introduzem na escola, permanece alheia ao tempo próprio do pensamento. Restringindo-se à esfera pragmática em detrimento da exigência prática da educação, os objetivos da pedagogia procedimental privam de todo fim, e de todo sentido, os alunos que não sabem por que vão à escola e que não têm nenhuma abertura para aquilo que os ultrapassa. É como bem nos lembra Kant, um fim é uma ideia da razão que, pela excelência de sua perfeição, comanda a experiência em vez de submeter-se a ela. Essa é, precisamente, a ideia da educação como fim moral da humanidade. Mas o fim não pode ser reduzido a uma série de objetivos a serem realizados seguindo-se cegamente os "procedimentos corretos". Definir a educação pelos objetivos, talvez, seja uma atitude pedagogicamente correta, ao menos para as sociedades contemporâneas que fizeram da utilidade um novo deus, mas nem por isso é uma atitude sensata. A correção é uma qualidade do comportamento que se inscreve nos procedimentos necessários para atingir um determinado objetivo. $\mathrm{O}$ sentido não é somente uma questão de procedimento. 
Sacrifica-se o sentido da educação submetendo o aluno aos métodos de controle denominados, como no caso de uma carteira de açóes, "avaliação" e que os gestionários da pedagogia que persistem em seu ser, isto é, na gestão, estão sempre avaliando, o que é a melhor maneira de se gerir a si mesmo. Avaliar não é educar: é dar um preço ao resultado de um procedimento conforme a utilidade social, medido segundo as exigências dos avaliadores, e também dar um preço à falta da eficácia pedagógica, medida segundo as práticas pedagógicas. Quanto às exigências do pensamento, parece-me não dizerem respeito às normas ministeriais que, segundo as palavras de Rousseau retomadas pelos saint-simosianos, interessam-se menos pelo governo dos homens que pela administração das coisas.

É preciso cuidado, como mencionei em outro espaço (Vicente, 2008), para que o sentido da educação não seja encoberto pelos interesses imediatos do Estado, da sociedade e do professor. Educar não significa integrar o sujeito nesta ou naquela comunidade nacional, profissional ou religiosa, mas despertá-lo para a comunidade humana, transcendente às épocas e às fronteiras. O seu conteúdo é o saber, que não é nem um saber-fazer, nem uma crença, mas um compreender, algo cujo caráter essencial é a reversibilidade. Isso não é um hábito e nem um saber de cor, é um compreender o que se sabe, para escapar a toda ordem temporal. Compreendemos um raciocínio, como mencionou Descartes (1977), quando podemos percorrer, nos dois sentidos, suas longas cadeias de razóes. Portanto, o sujeito só poderá conhecer e agir se começar primeiro a aprender a pensar, a fim de conseguir progressivamente pensar aquilo que aprende.

A educação está presente quando se tem em vista o homem e não o técnico, o profissional, o cidadão, o crente, ou seja, o sujeito a ser educado não deve ser entendido como condição para a materialização futura da vontade ou das metas preestabelecidas pelo "educador". Por isso não há necessidade de se cultivar, na educação, a ideia de uma autoridade (entendida não apenas como o poder de fazer-se obedecer, mas o fato de dar-se esse poder, por legítimo, seja porque a pessoa que o exerça o detenha em função de papel, tarefa, ou missão por cumprir, seja que o deva à sua superioridade, à sua ascendência, a seu prestígio), que faz dela uma relação vertical. É claro que existem teorias que pretendem justificar a autoridade, minimizando o seu impacto pela "intenção" que a anima, e a fundam na abnegação e no domínio de si, ou na caridade, como Laberthonnière (1935), mas não passam 
no teste. $\mathrm{O}$ que se percebe é que o próprio fim ou o sentido da educação é contradito pelos meios empregados para alcançá-lo. Às vezes, é bom observar a própria palavra "educação", que, do latim, como mostrei em outro trabalho (Vicente, 2009), proíbe que ela seja tomada no sentido já descrito, pois ela originou-se da raiz "e", que quer dizer "para fora", e de "ducere", que quer dizer "conduzir" ou "trazer". Assim, ela significa, de um modo simples e direto, revelar o que está dentro. Educar, portanto, não quer dizer "encher alguém de", mas "permitir que ele seja".

$\mathrm{O}$ indivíduo deve ser entendido em sua própria virtude. Educar não é fabricar homens segundo modelo comum, é, na sua forma mais simples e primitiva, liberar, em cada indivíduo, aquilo que o impede de ser ele mesmo, permitir-lhe realizar-se segundo seu gênio singular. O homem exige ser educado, mas não admite uma educação qualquer, apenas uma educação para si próprio, afinal, ele é um fim e não um meio. E como ensinou Kant (1968), a educação é uma elevação espiritual em direção a um fim transcendente. Em Roma, por exemplo, o pai legitimava o filho no dia do dies lustricus (dia da purificação) levantando-o do chão (tollere filium) e segurando-o no alto. Ele marcava com esse gesto público sua intenção de educá-lo para fazer dele um homem. Se ainda quisermos evitar que o homem sucumba a seus desejos, deixando livre curso a um certo grau de barbárie, é necessário acostumá-lo bem cedo a submeter-se às prescrições da razão. Não basta domar o homem, treiná-lo ou instruí-lo mecanicamente, importa prioritariamente que ele aprenda a pensar. A educação é uma orientação imanente à humanidade, que permite a cada um de nós encontrarmos o lugar certo no mundo.

Quem educa deve respeitar a forma imanente de cada educando. Educação deve permitir, necessariamente, a cada indivíduo encontrar seu estilo; ser ele mesmo, para além da espontaneidade incoerente, para além das normas prontas e acabadas e dos lugares-comuns; ser ele mesmo, assimilando o que cada cultura oferece de verdadeiramente humano, e recusar, inclusive, a educação conformista e anárquica que propóe limite susceptível de ser atingido de uma vez por todas, bloqueando, assim, o sujeito.

No processo educacional, o indivíduo não deve ser entendido ou reduzido a uma tábula rasa sobre a qual o "educador" tudo pode, e onde ele se apresenta como um engenheiro que vai trabalhar a matéria inerte. O educador, também, não é o "ministro da natureza", com a missão de "impedir o homem social de ser inteiramente artificial”, conforme as palavras de Rousseau 
(1951, p. 393). O indivíduo a ser educado deve ser entendido e admitido tal como é. Assim, ele poderá mudar, "progredir" e, finalmente, aceitar os outros. A mudança ocorre quando ele descobre que o seu "eu", tal como é, é plenamente aceito. $\mathrm{O}$ educador apenas deve, conforme as palavras de C. Rogers (1961, p. 133), "ajudá-lo a triunfar de suas inibiçóes para que ele possa ser ele mesmo". Então, em vez de criar conformistas e revoltados, a educação possibilitará o "aparecimento" de criadores numa época necessitada de criatividade, mas que parece insistir em não reconhecer o pensamento que exige do homem a excelência da criação em detrimento do mundo social da produção.

A educação precisa ser vista definitivamente como "negócio" dos educandos. Ou seja, centrada no instruir-se e não no instruir. Desse modo, o educador não deve falar sozinho, proibindo objeçóes e perguntas. Ser dogmático é confessar a própria fraqueza; não deve outorgar aos alunos o direito de palavra, ficando bem entendido que eles podem ter razão com ele, não contra ele. Quando o educador não admite correr o risco de náo ter razão, de admitir outro ponto de vista, de aparecer desgastado pelos hábitos, ele corre o risco de abafar, de extinguir no aluno o pensamento, o gênio. Quem não admite correr o risco de ser ensinado, não deve ensinar. $\mathrm{O}$ educador não é aquele que está acima do educando, é aquele que está com ele. Não é por acaso que J. Holt (1966) ensinou que é impossível uma verdadeira educação enquanto pensamos e acreditamos que é nosso dever e nosso direito impor aos alunos o que eles devem aprender.

De um modo geral, quando se entende a educação como dever de apontar ao outro o que ele deve aprender, o educador é sempre tentado, de uma forma contundente, a encontrar sua "superioridade" na própria "inferioridade" do indivíduo que ele educa. Dessa forma, a educação vira arma, ou seja, o conhecimento dos indivíduos e dos meios de instruí-los é, também, o que permite dominá-los, manejá-los. Todavia, como um meio, esse entendimento sobre a educação não é ameaçador, o perigo está em transformá-lo como fim. Assim, o educador se rebaixa ao nível do anunciante publicitário, unicamente interessado em "vender", sem se interessar, de modo algum, pela qualidade daquilo que vende, apresenta-se como homem competente para "vender", por exemplo, matemática, história, ética, inglês, física, geografia, etc., mas recusa-se tenazmente a refletir sobre o que ensina. Quando se acostuma com uma técnica, de repente, ela se torna rotina; quando se acostuma com uma ciência qualquer, de repente, ela se torna 
dogmática. Talvez essas sejam as razóes pelas quais os considerados como maiores teóricos da educação raramente fizeram dela um ofício (Montaigne, Rousseau, Montessori, Dewey), e aqueles que foram educadores de ofício começaram pela revolta contra ela (Makarenko, Freinet).

A educação, portanto, deve permitir, necessariamente, que o homem pense, pois o pensamento é o hiato que permite ao sujeito suspender uma ação, interromper um processo, estabelecer uma ruptura numa rede tecida de desejos e carências, necessidade e submissão, que é o fluxo contínuo da vida. O pensamento permite ao homem olhar a si próprio como sendo, a cada instante, um começo absoluto, um initium. Só o pensamento tem o poder de interromper o encadeamento da vida animal. Nunca se deve esquecer: o homem possui, como ensinou Schiller (1992), uma disposição eterna para atualizar o infinito do possível, o que nada mais é, no começo de cada uma de suas açóes, que tomar consciência de sua liberdade. Essa disposição eterna não deve ser dispensada e nem ignorada por nenhum tipo de educação, mas despertada. Por isso, antes de educar, é preciso colocar a pergunta radical: que é o homem para que deva ser educado?

\section{Referências}

ARENDT, H. Eichmann em Jerusalém. São Paulo: Companhia das Letras, 1999.

. Origens do totalitarismo. São Paulo: Companhia das Letras, 1989.

BAUMAN, Z. Em busca da política. Rio de Janeiro: Zahar, 2000.

DESCARTES, R. Discours de la méthode. Paris: Gallimard, 1977.

DEWEY, J. Schools of tomorrow. New York: Putman, 1931.

. The philosopher of the common man. New York: Putman, 1940.

. My pedagogic creed. New York: Kellog \& Co., 1957.

DURKHEIM, E. Les règles de la méthode sociologique. Paris: Gallimard, 1975. 
KANT, I. Grundlegung zur metaphysik der sitten. Berlim: Akademie Verlag, 1970. . Über pädagogik. Berlim: Akademie Verlag, 1968.

HOLT, J. Parents et maitres devant l'echec scolaire. Tournaim: Costerman, 1966.

LABERTHONNIÈRE, L. Théorie de l'éducation. Paris: Vrin, 1935.

MACRIDIS, R. Ideologias politicas contemporâneas. Brasília: UnB, 1982.

ROGERS, C. On becoming a person. Boston: Houghton Mifflin, 1961.

ROUSSEAU, J-J. Emile ou de l'éducation. Paris: Garnier, 1951.

SCHILLER, F. Lettres sur l'éducation esthétique de l'homme. Paris: Aubier, 1992.

TOURAINE, A. O que é democracia? Rio de Janeiro: Vozes, 1996.

VICENTE, J.J.N.B. Reflexôes e posicionamentos. Goiânia: Ed. Vieira, 2009. . Sentido da educação. Revista Facer, Rubiataba, GO, v. 7, n. 1, p. 51-58, fev. 2008. A educação funcional. Revista Facer, Rubiataba, GO, v. 3, n. 3, p. 41-48, fev. 2006. 